\title{
USE OF THE HOME VCR TO FACILITATE TRANSFER OF FLUENCY
}

\author{
DAVID A. DALY \\ University of Michigan, Ann Arbor, Michigan
}

\begin{abstract}
Many stuttering clients experience difficulty in transferring fluency observed during treatment back into the home environment. Several explanations for this regression to a priori levels of stuttering are offered. Use of video recording during treatment and subsequent viewing by parents or spouses at home are suggested. Two clinical examples describe how video cassette recorder technology can be employed to facilitate transfer of fluency in suttering clients.
\end{abstract}

It is not uncommon for a stuttering client, who has demonstrated good progress establishing fluency in therapy, to encounter considerable difficulty when attempting to transfer the fluency skills back into the home environment. Some adults who have enjoyed improved fluency at work may fail to achieve similar levels of fluency with their spouse at home. School-age stutterers may be reading aloud more fluently and speaking much better with teachers and classmates, yet maintain near original levels of stuttering behaviors at home with parents. It is ironic that the people who the client is closest to frequently are the last ones to see and hear any real progress. Occasionally, spouses or parents may express their concerns or doubts about the benefits of treatment. Such negative statements may undermind the client's confidence and have deleterious effects on treatment. Sometimes even innocent inquiries about how much time therapy is taking can cause a client to question himself or herself and effect a setback. In most cases, support from the home environment is necessary for transfer of fluency.

In cases where parents report little or no improvement in fluency at home, we have found the use of home video cassette playback machines to be of tremendous value. Two examples of our use of the video cassette recording (VCR) instrumentation are reported. Our first use of the client's home VCR unit occurred quite by accident. As a 13-year-old stuttering

Address correspondence to David A. Daly, EdD, Associate Professor, Speech and Language Pathology, University of Michigan, 1111 East Catherine Street, Ann Arbor, Michigan 48109. 
client and I were reviewing a videotape of him talking fluently during telephone calls made in therapy, he exclaimed, "Boy, I wish my dad could see this tape. He doesn't think I'm getting any better at all." On learning that his family owned their own VCR unit, I offered to loan him the tape. My only request was that in addition to showing his progress to his parents, he carefully watch himself talking smoothly and effortlessly on the tape for at least 5 minutes each day. I requested that he focus on the positive aspects of his speech (i.e., the speech behaviors that enabled him to talk fluently).

During our next session, the boy returned my tape, but brought a blank one of his own to record other successes for subsequent review at home. He told me how pleased his dad was when he watched the tape. Moreover, the repeated viewings of the tape had the positive effect of putting in this client's mind images that he, indeed, was fluent, that his fluency was improving, and that he would be even more fluent in the future.

The other example is a 30-year-old attorney who was quite outgoing and verbose despite his moderately severe cluttering and stuttering behaviors. He responded very well to treatment (see Daly, 1986 for therapy suggestions) and soon was making telephone calls in therapy. We videotaped his performance during carefully planned phone call contracts and replayed the cassette, pointing out all his successfully executed speech targets. He was fascinated to see himself speaking so fluently and asked if he could borrow the cassette to show to his wife. She accompanied him to therapy during the next session. Her comment to the clinician was, "Who was that man on the tape? I have been married to Russ for 4 years, and have never seen him that fluent on the phone before." Since viewing the cassette, her attitude towards the benefits of therapy changed, and she became more of a positive influence. His fluency began to transfer into the home environment from this point.

In retrospect, there may be very plausible reasons why some stuttering individuals maintain their stuttering at home, even when progress is noted elsewhere. Children typically feel quite comfortable stuttering in front of their parents. For months or even years, parents may have told the stuttering child that they love him or her even if they do stutter, and that it doesn't bother them. Similar statements could be made by spouses.

Talking fluently does require concentration and extra work. After monitoring their speech all day at school or at work, some stutterers may elect (consciously or unconsciously) to let down their effort at home. Home is one place where the stutterers may feel that they can just relax; a place where they do not have to be "on guard." Home is the place where it is possible to lower that protective shield for awhile. Some individuals may view their home as a relaxed, comfortable environment that will tolerate or allow dysfluencies to occur without punishment or castigation.

Stuttering may persist at home because the parent's responses that initially contributed to the stuttering in the first place may have returned. 
Occasionally, concerned parents respond very well to speech clinicians' initial suggestions for facilitating fluency. Perkins (1979) described several ways in which parents may alter behaviors that could be aggravating or maintaining their child's stuttering. As clients begin to demonstrate some progress, however, it is not uncommon for parents to unconsciously revert back to their previous response patterns. Some of our stuttering clients leave the calm, supportive setting of the therapy room only to return to a demanding, interrupting, rapid-paced environment at home. In such cases, parent counseling and a review of new response patterns that facilitate fluency are necessary. Review of fluency targets and monitoring procedures may be accomplished through direct parent/spouse conferences or by sending instructions and examples home with the client via videotape. Communication through videotape and modeling of desired responses are particularly important for parents who are helping their children with speech practice at home. Perkins (1979) has made a strong case for teaching parents by example rather than by direction. Periodic viewing of videotaped segments of therapy in which the clinician coaches and reinforces correct execution of precise speech targets can be a powerful instruction medium for the parents and the child.

Even before attempting outside transfer situations, our goal with the stuttering client has been to have them "see" themself speaking fluently in as many different situations and with as many different people as possible. We (Daly et al., 1985) have found Lazarus' (1984) visual imagery procedures exceedingly helpful in this regard. The goal of such visualization exercises is to replace negative, fearful memories of stuttering, with new, more positive images of themselves talking fluently. Clients are instructed to relax, close their eyes, and visualize themselves speaking fluently; first in one situation, then in another. Clients' abilities to picture themselves clearly in such situations were greatly varied. A few achieved success with mental imagery right away; others reported improvement with repeated practice. Some clients, however, reported poor success in "seeing" themselves fluent. In their mind's eye all they could visualize were past experiences of speech failure (i.e., their mental pictures were full of stuttering memories or images).

For these clients, we incorporated the use of videotape more and more in therapy. Clients then viewed themselves speaking fluently on automatic tasks (counting or naming days of the week) and on echoic tasks in which they repeated words after the clinician. Next, they saw themselves reading word lists and short sentences aloud.

As these clients are able to "see" themselves talking fluently in more situations, we ask them to listen also to their own fluent voices with great care. Our objective is to develop a new auditory image of this fluent self in their "mind's ear." So often, the stutterer has listened to any and every possible speech dysfluency or "stickiness" for so long that they stop listening to their own fluent speech. Our task here is to awaken their 
awareness to their new smooth speech. Both clinical observations and client reports suggest that development of the new auditory image of fluency is as important to lasting change as developing the new visual image. Both auditory and visual imagery have proved beneficial in facilitating the transfer of fluency.

Thus, far, we have explored the VCR transfer procedure with 12 stuttering clients. All have reported positive reactions from family members who cannot sit in on therapy. Parents of adolescent clients have commented that their children are particularly proud of their speech progress and no longer are sensitive about or resistant to explaining the fluency targets and homework assignments to them. Surprisingly, the majority of our clients or their parents already owned home video recorders and were happy to provide a blank cassette for future recording. Now, along with written practice material and speech contract sheets, many clients arrive for therapy with a video cassette under their arm. Perhaps the old speech notebook will soon be replaced or supplemented with videotapes? Families who did not own a VCR agreed to periodically rent one so that their child could demonstrate to them at home the progress being made. The charge for renting a playback machine for an evening is nominal.

This videotaping procedure may be difficult in some university clinics and hospitals, but it is possible. It has been our experience that most private practices and intermediate school districts have videotaping capabilities too. Such procedures will most likely involve some red tape and inconvenience; however, the benefits to the clients and their families make the extra efforts exceedingly worthwhile.

In summary, use of a home videotape playback machine to view and review tapes made in the clinical facility during stuttering treatment is recommended. The client can "see" and "hear" himself or herself correctly producing the speech targets being taught. Parents, siblings, spouses, or friends can view the progress in the comfort of their own home. The tape may also be used to communicate specific directions to parents or spouses about ways they can help at home. If necessary, the tape can be reviewed again and again. We encourage this use of VCR technology to facilitate transfer of fluency in clients who stutter.

\section{REFERENCES}

Daly, D.A. The clutterer. In St. Louis, K. (ed.). The Atypical Stutterer: Principles of and Remediation. New York: Academic Press, 1986.

Daly, D.A., Thompson, J.D., and Simon, C.A. Treatment of cluttering with stutter-free speech and mental imagery. Paper Presented at the Annual Convention of the Speech-Language-Hearing Association, Cincinnati, 1985.

Lazarus, A. In the Mind's Eve. New York: Guilford Press, 1984.

Perkins, W.H. From psychoanalysis to discoordination. In Gregory, H. (ed.). Controversies About Stuttering Therapy. Baltimore: University Park Press, 1979. 